\title{
Survey on Natural Occurrence of Endophytes in Maize (Zea mays L.) Ecosystem
}

\author{
S.N. Bhagyasree ${ }^{1 *}$, S.K. Ghosh ${ }^{2}$, M. Thippaiah ${ }^{3}$ and N.N. Rajgopal ${ }^{1}$ \\ ${ }^{1}$ Indian Agricultural Research Institute, New Delhi-110012, India \\ ${ }^{2}$ Deputy General Manager, R\&D, Multiplex Biotech Private limited, Bengaluru -560058, \\ Karnataka, India \\ ${ }^{3}$ University of Agricultural Sciences, GKVK, Bengaluru-560065, Karnataka, India \\ *Corresponding author
}

\begin{tabular}{|c|c|}
\hline & B S T RA C T \\
\hline & \multirow{5}{*}{$\begin{array}{l}\text { Fungi that occur inside an asymptomatic plant tissue are known as fungal endophytes. } \\
\text { Since a decade there has been high focus on artificial establishment of entomopathogenic } \\
\text { fungi as an endophyte in various agricultural and horticultural crops for pest management. } \\
\text { But meagre efforts are made to identify their natural occurrence. Keeping this in view, } \\
\text { Survey has been conducted in maize at definite phenophases of crop growth i.e. Seedling } \\
\text { stage, knee height stage and reproductive stage. Nine genera of fungus i.e., Aspergillus } \\
\text { spp., Beauveria spp., Fusarium spp., Lecanicillium spp., Metarhizium spp., Mucor spp. } \\
\text { Penicillium spp., Rhizopus spp. and Trichoderma spp. were isolated as naturally occurring } \\
\text { entomopathogenic fungal endophytes. Percent colonisation of endophytic fungi was high } \\
\text { at seedling stage ( } 16.66 \pm 10.03) \text { followed by knee height stage (14.22 } \pm 5.77) \text { and the } \\
\text { least at reproductive stage }(13.22 \pm 6.00) \text {. Thus, the study indicates the potential of natural } \\
\text { establishment of endophytes after repeated and continuous use of entomopathogenic } \\
\text { fungus for pest management. }\end{array}$} \\
\hline Keywords & \\
\hline $\begin{array}{l}\text { Colonisation, } \\
\text { Endophyte, } \\
\text { Entomopathogenic, } \\
\text { Maize and Phenophase }\end{array}$ & \\
\hline Artic & \\
\hline $\begin{array}{l}\text { Accepte } \\
20 \text { Dece } \\
\text { Availab } \\
10 \text { Ianu }\end{array}$ & \\
\hline
\end{tabular}

\section{Introduction}

Since many decades, agrochemicals have been deliberately used by farmers for insect pests management in maize, but their adverse effect on non-target organisms, ground water contamination, environmental pollution, residues on the food crops, resistance development and resurgence in insects lead researchers to focus on the development of alternative which are biologically based. One of that alternative includes entomopathogens, because these are proved to be the $>90$ per cent mortality factors in the laboratory bioassay on wide range of insect pests. Even though they are effective, their field application has been limited because of high temperature, low humidity and improper delivery methods. In order to overcome these current bottlenecks, unexpected role played by fungal entomopathogens i.e., their presence as fungal endophytes has been sought (Vega et al., 2009). Endophytes inhibit relatively privileged niche within the plants symbiotically and contribute to plant health asymptomatically by increasing the plant 
fitness against abiotic and biotic stress. Their ecological significance in plant growth (Sasan and Bidochka, 2012; Elena et al., 2011), herbivore resistance (Bing and Lewis, 1991; Akello et al., 2008a; Gurulingappa et al., 2011; Akello et al., 2008b) and disease resistance (Ownley et al., 2008; Ownley et al., 2010) are diverse and versatile. The herbivory resistance mechanism expressed by endophytes was correlated to toxin production (Lattanzio et al., 2006) and increase in the secondary metabolite and variation in the biochemical titter (Bhagyasree, 2013).

In past two decades, a great deal of information available on the artificial endophytic association of Beauveria bassiana (Balsamo) Vuillemin in various commercial crops which includes, maize (Bing and Lewis, 1991), tomato (Ownley et al., 2004), opium poppy (Quesada-Moraga et al., 2006), date palm (Go'mez-Vidal et al., 2006), bananas (Akello et al., 2007), coffee (Posada et al., 2007) and common bean (Soroush Parsa et al., 2013). As the fungus is capable of colonising inside the plant tissue through artificial inoculation imitates the probability of its natural occurrence after continuous application of entomopathgens for managing the pests. But, information on the natural occurrence is very limited. Keeping this in view, attempts were made to conduct the survey to isolate and quantify the naturally occurring fungal entophytes in maize ecosystem to provide baseline information on diversity for further utilization in pest management.

\section{Materials and Methods}

Survey was conducted in continuous maize growing field near Bio control Research Laboratory, Pest Control India private limited, Rajanukuntae, Bangalore, Karnataka at definite phenophases of crop growth i.e. seedling stage, knee height stage and reproductive stage during kharif season, where, entomopathogens were continuously used by farmers for management of insect pest. Ten maize plant were randomly uprooted and brought to laboratory for isolation and identification of fungal endophytes according to the protocol described by Petrini (1986) with slight necessary modifications. Roots, stems and leaves were separated and gently washed with tap water and surface sterilized with 1 per cent sodium hypochlorite solution containing 0.05 per cent tween-80 soap solution for 3 minutes and 75 per cent ethanol for 1 minute. Later plant samples were rinsed thrice in sterile distilled water and then placed on a sterile tissue paper in a bio safety cabinet. Ten each samples of root, stem and leaf of approximately 2 to $3 \mathrm{~mm}^{2}$ size were placed separately on PDAY (Potato Dextrose Agar Y) medium and incubated at $20-23^{\circ} \mathrm{C}$ (Fig. 1). A total 300 plant pieces at seedling stage, 300 at knee height stage and 300 at reproductive stage were examined. To check the efficacy of the surface sterilization, $20 \mathrm{ml}$ of water which is used to rinse the tissue after sterilization was taken and $20 \mu \mathrm{l}$ of aliquots of $10^{-3}$ dilutions were plated on the PDAY media and spread with a sterile glass rod, incubated at $20-23^{0} \mathrm{C}$ for colony forming units. However the sterilization resulted in no growth of fungus inferred that fungus has originated from internal plant tissues (Tefera and Vidal, 2009). The presence or absence of naturally occurring endophytic growth on the samples were recorded after 7 days based on the colony characters, colour and morphology of the reproductive structures.

\section{Statistical analysis}

The per cent colonization of fungi was expressed using the formula, Colonisation frequency $=100 \mathrm{X}$ (number of plant piece colonized by each endophyte / total no of piece evaluated). The per cent colonisation data were arc sine transformed to stabilize the 
variance and subjected to ANOVA in the Web Based Agricultural Statistics Software Package (WASP 1.0). Overall colonisation at each phenophases was estimated by pooling the mean value of root, stem and leaves of each fungus.

\section{Results and Discussion}

This is the first report on the isolation of naturally occurring entomopathogenic fungal endophyte in agriculturally important commercial crops. The results indicates that, there were 9 genera of fungus which have characteristic feature of colonising endophytically in the plant system, which includes, Aspergillus spp., Beauveria spp., Fusarium spp., Metarhizium spp., Mucorspp., Penicilliumsp., Rhizopus spp., Trichoderma spp. and Lecanicillium spp. (Fig. 2-4). Among them, 7 genera of fungus i.e., Aspergillus spp., Beauveria spp., Fusarium spp., Metarhizium spp., Penicillium spp., Trichoderma spp. and Lecanicillium spp. are known to be entomopathogenic. In other similar studies, Aspergillus sp., Curvularia sp., Geotrichum sp., Gliocladium sp. and Colletotrichum sp. in cocoa plants (Amin et al., 2014) and Acremonium spp., Aspergillus spp., Cladosporium spp. and Penicellium spp. from cocoa pods (Posada et al., 2010) were isolated as natural endophytes. This enormous amount of versatility without causing any adverse effect indicates the strong association between fungus and the maize plant.

Among all isolates colonization of the Trichoderma spp. (33.33 \pm 2.72$)$ was the highest followed by Penicillium spp. (25.66 \pm 5.36), Lecanicillium spp. (23.66 \pm 0.88), Aspergillus spp. (19.66 \pm 6.11$)$ Fusarium spp. (13.33 \pm 2.90$)$, Rhizopus spp. (9.66 \pm 2.40$)$, Metarhizium spp. (7.66 \pm 0.66), Beauveria spp. (5.33 \pm 0.33$)$, and the least colonization was noticed in Mucor spp. (2.66 \pm 1.70 ). Colonization of endophytes was high and significant in roots $(\mathrm{P}<0.05)$, where as in case of stem and leaves, colonisation was poor and non-significant $(\mathrm{P}>0.05)$. In addition to plant parts colonised, percent colonisation was also differed at different growth phases i.e. seedling stage had highest colonisation percentage with total of $16.66 \pm 10.33$, followed by knee height stage with $14.22 \pm$ 5.77 and the least at reproductive stage with $13.22 \pm 6.00$ (Table 1).

The present survey revealed that, apart from artificial establishment of entomopathogenic fungi as endophytes through various inoculation techniques, there is a probability of natural occurrence to some extent after their continuous application in the field for pest management. However, the level of colonisation seems to be substantially affected due to the various biotic, abiotic, edaphic and genetic factors.

Among the isolated fungal species, the highest colonisation rate of Trichoderma sp., Penicillium spp., Lecanicillium spp. and Aspergillus spp. may be due to presence of high amount of primary inoculums in the soil.

Endophytic colonization was also noticed in the stem, where they move from the roots through apoplast movement and colonize in the pith region of the stem to some extent. The bestowed versatility and diversity in roots is due to the favourable microclimatic condition and availability of enormous amount of primary inoculums and organic matter in the soil. There was a downstream colonization in leaves claims to unfavourable climatic condition, compact arrangement of mesophyll cells and increased exposure to agrochemicals and sunlight. Variation in the extent of colonization in roots, stem and leaves clearly indicates that fungus exhibits some tissue specificity and relay on the microclimatic and moisture condition of the plant system for their endophytic colonization. 
Fig.1 Surface sterilization and isolation technique

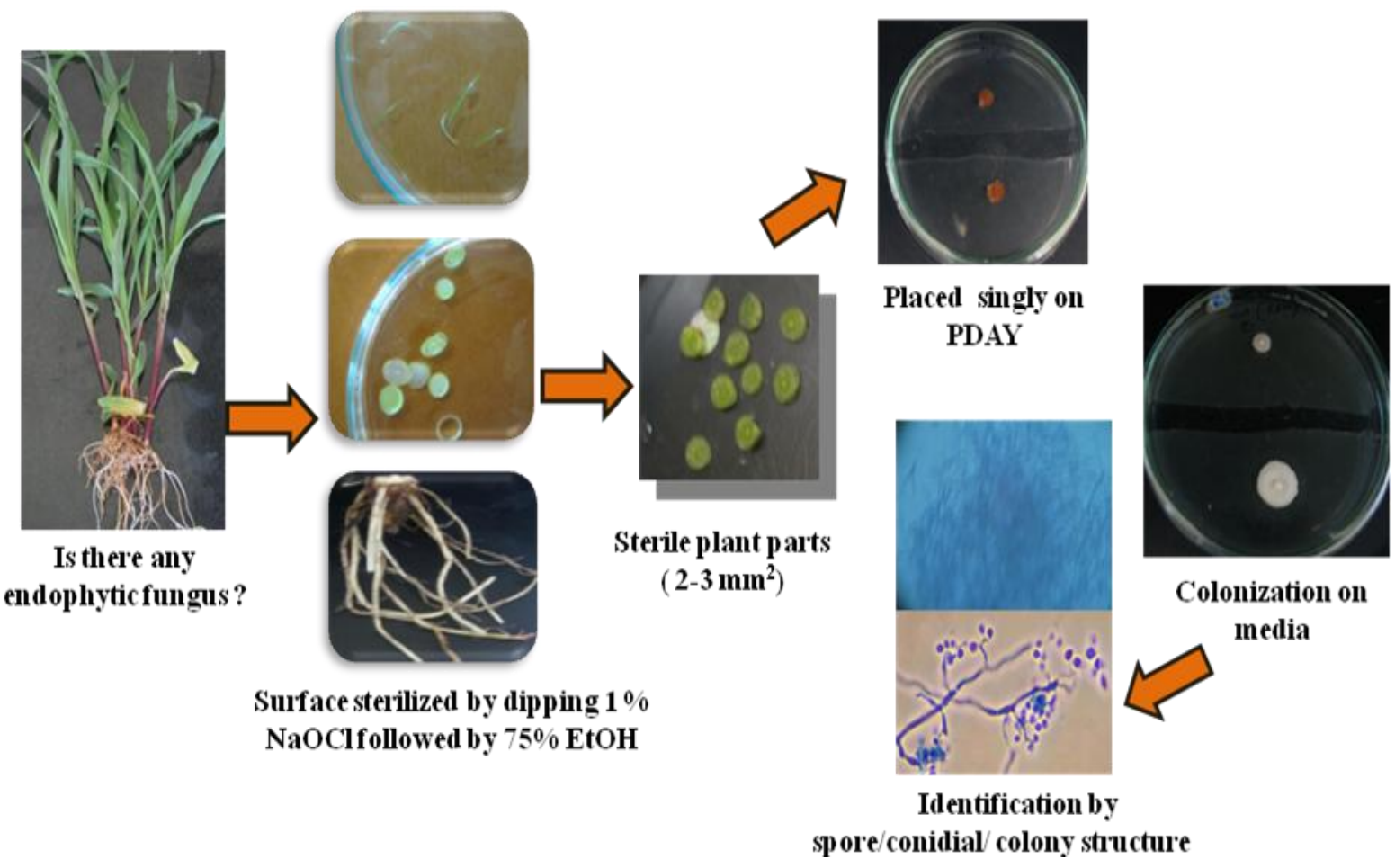

Fig.2 Mean ( \pm SE) percent colonization of natural occurring fungus isolated in roots at different phenophases (SS: seedling stage; KHS: knee height stage and RS: reproductive stage)

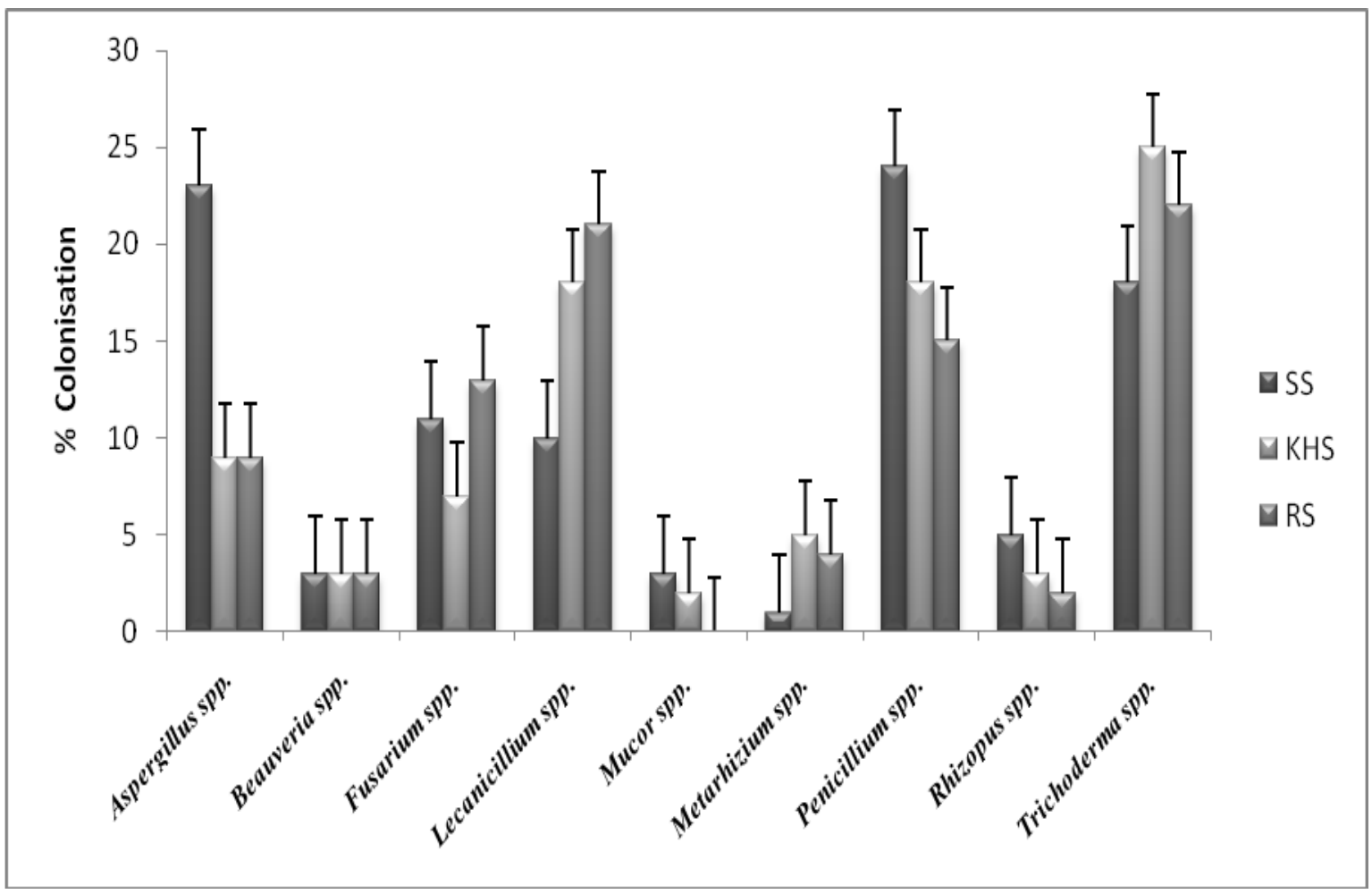


Fig.3 Mean $( \pm \mathrm{SE})$ percent colonization of natural occurring fungus isolated in roots at different phenophases (SS: seedling stage; KHS: knee height stage and RS: reproductive stage)

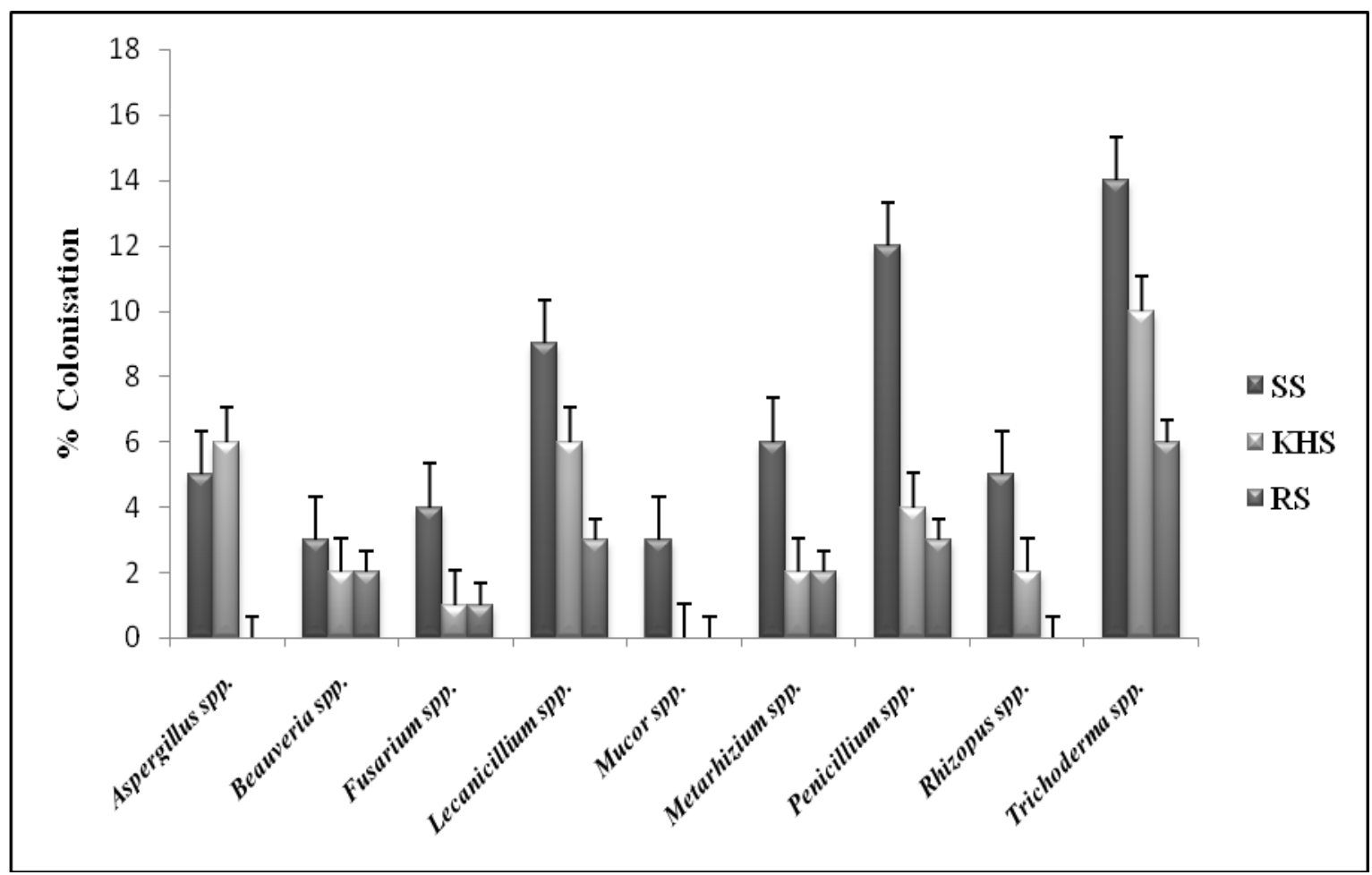

Fig.4 Mean $( \pm$ SE) percent colonization of natural occurring fungus isolated in leaves at different phenophases (SS: seedling stage; KHS: knee height stage and RS: reproductive stage)

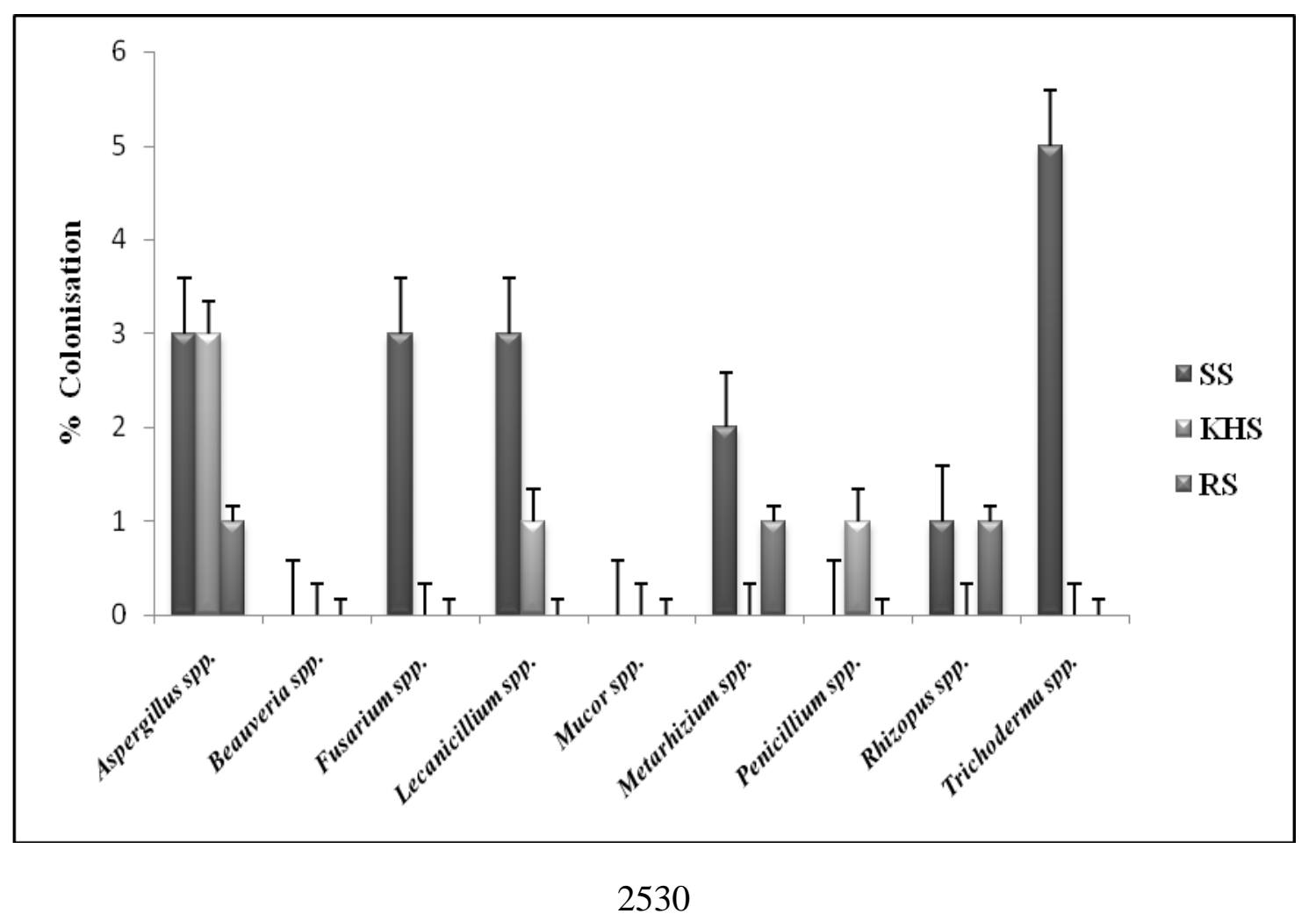


Table.1 Overall colonization of fungus at different phenophases (mean \pm SE)

\begin{tabular}{|l|c|c|c|c|}
\hline Genera of fungus & $\begin{array}{c}\text { Overall \% } \\
\text { colonization at } \\
\text { seedling stage }\end{array}$ & $\begin{array}{c}\text { Overall \% } \\
\text { colonization at } \\
\text { knee height stage }\end{array}$ & $\begin{array}{c}\text { Overall \% } \\
\text { colonization at } \\
\text { reproductive stage }\end{array}$ & $\begin{array}{c}\text { Average \% } \\
\text { colonization } \\
\text { in whole plant }\end{array}$ \\
\hline Aspergillus spp. & $31 \pm 6.35$ & $18 \pm 1.73$ & $10 \pm 2.84$ & $19.66 \pm 6.11$ \\
\hline Beauveria spp. & $06 \pm 1.00$ & $05 \pm 0.88$ & $05 \pm 0.88$ & $05.33 \pm 0.33$ \\
\hline Fusarium spp. & $18 \pm 2.51$ & $08 \pm 2.10$ & $14 \pm 4.17$ & $13.33 \pm 2.90$ \\
\hline $\begin{array}{l}\text { Lecanicillium } \\
\text { spp. }\end{array}$ & $22 \pm 1.00$ & $25 \pm 5.04$ & $24 \pm 6.55$ & $23.66 \pm 0.88$ \\
\hline Mucor spp. & $06 \pm 1.52$ & $02 \pm .066$ & 0 & $02.66 \pm 1.70$ \\
\hline $\begin{array}{l}\text { Metarrhizieum } \\
\text { spp. }\end{array}$ & $09 \pm 6.92$ & $07 \pm 1.45$ & $07 \pm 0.88$ & $07.66 \pm 0.66$ \\
\hline Penicillium spp. & $36 \pm 1.33$ & $23 \pm 5.23$ & $18 \pm 4.55$ & $25.66 \pm 5.36$ \\
\hline Rhizopus spp. & $11 \pm 3.84$ & $05 \pm 0.88$ & $13 \pm 3.84$ & $09.66 \pm 2.40$ \\
\hline Trichoderma spp. & $37 \pm 1.66$ & $35 \pm 7.20$ & $28 \pm 6.55$ & $33.33 \pm 2.72$ \\
\hline $\begin{array}{r}\text { Average } \\
\text { colonization of all } \\
\text { endophytes }\end{array}$ & $\mathbf{1 6 . 6 6 \pm \mathbf { 1 0 . 0 3 }}$ & $\mathbf{1 4 . 2 2} \pm \mathbf{3 . 7 7}$ & $\mathbf{1 3 . 2 2} \pm \mathbf{6 . 0 0}$ & \\
\hline
\end{tabular}

Movement of fungus from roots to stem and to leaves indicates that transmission is vertical from seeds.

Colonisation was also varied with respect to different phenophases similar to plant parts. During seedling stage, fungal diversity and colonisation was high compared to knee height and reproductive stage, this could be due to the reduction in succulence, interference of agrochemicals and interaction among the fungi. Finally it's imperative to know more about ecology, fungus plant interaction, role of fungi in improving the fitness in order to exploit them in better way as biological control agents. This current research throws a light on new paradigm for biological control in case of entomopathogenic fungi.

\section{References}

Akello, J., Dubois, T., Coyne, D. and Kyamanywa, S., 2008a. Effect of endophytic Beauveria bassiana on populations of the banana weevil, Cosmopolites sordidus, and their damage in tissue- cultured banana plants. Entomologia experimentalis et applicata, 129(2), pp.157-165.

Akello, J., Dubois, T., Coyne, D. and Kyamanywa, S., 2008b. Endophytic Beauveria bassiana in banana (Musa spp.) reduces banana weevil (Cosmopolites sordidus) fitness and damage. Crop protection, 27(11), pp.1437-1441.

Akello, J., Dubois, T., Gold, C.S., Coyne, D., Nakavuma, J. and Paparu, P., 2007. Beauveria bassiana (Balsamo) Vuillemin as an endophyte in tissue culture banana (Musa spp.). Journal of invertebrate pathology, 96(1), pp.34-42.

Amin, N., Salam, J. M. and Asman, B., 2014. Isolation and identification of endophytic fungi from cocoa plant resistante VSD M. 05 and cocoa plant Susceptible VSD M. 01 in South Sulawesi, Indonesia. International Journal of Current Microbiology and 
Applied Sciences. 3(2):459-67.

Bhagyasree, S.N., 2013. Studies on interaction between endophytic Beauveria bassiana (balsamo) and maize stem borer, Chilo partellus (swinhoe) (Crambidae: Lepidoptera). Masters dissertation, University of Agricultural Sciences GKVK, Bangalore.

Bing, L.A. and Lewis, L.C., 1991. Suppression of Ostrinia nubilalis (Hübner) (Lepidoptera: Pyralidae) by endophytic Beauveria bassiana (Balsamo) Vuillemin. Environmental entomology, 20(4), pp.1207-1211.

Elena, G.J., Beatriz, P.J., Alejandro, P. and Lecuona, R.E., 2011. Metarhizium anisopliae (Metschnikoff) Sorokin promotes growth and has endophytic activity in tomato plants. Advances in Biological Research, 5(1), pp.22-27.

Gómez-Vidal, S., Lopez-Llorca, L.V., Jansson, H.B. and Salinas, J., 2006. Endophytic colonization of date palm (Phoenix dactylifera L.) leaves by entomopathogenic fungi. Micron, 37(7), pp.624-632.

Gurulingappa, P., Sword, G.A., Murdoch, G. and McGee, P.A., 2010. Colonization of crop plants by fungal entomopathogens and their effects on two insect pests when in planta. Biological control, 55(1), pp.34-41.

Lattanzio, V., Lattanzio, V.M. and Cardinali, A., 2006. Role of phenolics in the resistance mechanisms of plants against fungal pathogens and insects. Phytochemistry: Advances in research, pp.23-67.

Ownley, B.H., Griffin, M.R., Klingeman, W.E., Gwinn, K.D., Moulton, J.K. and Pereira, R.M., 2008. Beauveria bassiana: endophytic colonization and plant disease control. Journal of invertebrate pathology, 98(3), pp.267270.
Ownley, B.H., Gwinn, K.D. and Vega, F.E., 2010. Endophytic fungal entomopathogens with activity against plant pathogens: ecology and evolution. BioControl, 55(1), pp.113128.

Ownley, B.H., Pereira, R.M., Klingeman, W.E., Quigley, N.B. and Leckie, B.M., 2004. Beauveria bassiana, a dual purpose biocontrol organism, with activity against insect pests and plant pathogens. Emerging Concepts in Plant Health Management. Research Signpost, India, pp. 255-269.

Parsa, S., Ortiz, V. and Vega, F.E., 2013. Establishing fungal entomopathogens as endophytes: towards endophytic biological control. Journal of visualized experiments: JoVE, (74).

Petrini, O., 1986. Taxonomy of endophytic fungi of aerial plant tissues. Microbiology of the phyllosphere/edited by NJ Fokkema and J. van den Heuvel.

Posada, F., Aime, M.C., Peterson, S.W., Rehner, S.A. and Vega, F.E., 2007. Inoculation of coffee plants with the fungal entomopathogen Beauveria bassiana (Ascomycota: Hypocreales). Mycological research, 111(6), pp.748757.

Posada, F.J., Chaves, F.C., Gianfagna, T.J., Pava-Ripoll, M. and Hebbar, P., 2010. Establishment of the fungal entomopathogen Beauveria bassiana as an endophyte in cocoa pods (Theobroma cacao L.). Revista UDCA actualidad and divulgación científica, 13(2), pp.71-78.

Quesada-Moraga, E., Landa, B.B., MuñozLedesma, J., Jiménez-Diáz, R.M. and Santiago-Alvarez, C., 2006. Endophytic colonisation of opium poppy, Papaver somniferum, by an entomopathogenic Beauveria bassiana strain. Mycopathologia, 161(5), pp.323- 
329.

Sasan, R.K. and Bidochka, M.J., 2012. The insect-pathogenic fungus Metarhizium robertsii (Clavicipitaceae) is also an endophyte that stimulates plant root development. American Journal of Jotany, 99(1), pp. 101-107.

Tefera, T. and Vidal, S., 2009. Effect of inoculation method and plant growth medium on endophytic colonization of sorghum by the entomopathogenic fungus Beauveria bassiana. BioControl, 54(5), pp. 663-669.

Vega, F.E., Goettel, M.S., Blackwell, M., Chandler, D., Jackson, M.A., Keller, S., Koike, M., Maniania, N.K., Monzon, A., Ownley, B.H. and Pell, J.K., 2009. Fungal entomopathogens: new insights on their ecology. Fungal Ecology, 2(4), pp. 149-159.

\section{How to cite this article:}

Bhagyasree, S.N., S.K. Ghosh, M. Thippaiah and Rajgopal, N.N. 2018. Survey on Natural Occurrence of Endophytes in Maize (Zea mays L.) Ecosystem. Int.J.Curr.Microbiol.App.Sci. 7(01): 2526-2533. doi: https://doi.org/10.20546/ijcmas.2018.701.303 